\title{
Calorie labelling of meals in a university catered hall; opinions of students and reported effects on meal choice
}

\author{
C. K. Nikolaou, M. Lean and C. R. Hankey \\ College of Medical, Veterinary and Life Sciences, School of Medicine, GRI Campus, Walton Building, Glasgow Royal \\ Infirmary, 84 Castle Street, Glasgow G4 OSF, United Kingdom
}

\begin{abstract}
Weight gain in young adulthood often persists across the life-course, favouring the development of obesity and overweight. Calorie labelling in catering outlets has been used in various commercial and geographic settings, such as New York City, in an attempt to tackle the obesity epidemic. Providing information on calorific values on prepared meals at the point of choice may guide students to consume fewer calories and assist in preventing unintentional weight gain. The aim of this study was to explore whether labelling meals can influence students' meal choices and calorie consumption for meals served at an institutional catering setting. The energy content of the usual menu of a catered student hall of residence where 2 meals daily were provided on weekdays, and 1 breakfast/lunch on weekend days was analysed using with nutritional analysis software (WinDiets, 2010) according to Department of Health Guidelines ${ }^{(1)}$. Calorie-range for each course was; starters 18-462 kcal, main course 206-952 kcal and for desserts 169-682 kcal. Calorie-range for a three-course meal was 393-2096 kcal. Calories for each menu choice for evening meals provided were posted daily at the point of service throughout the 5 week menu cycle. After the 5 week period students resident in the hall were emailed an evaluation questionnaire seeking their views on and use of calorie posting. Responses were collected anonymously on a commercial website. 42 students completed the evaluation questionnaire at the end of the calorie posting period, a response rate of 35\%. Mean age of the participants was 19.7 SD 2.2 years old, mean self-reported body weight 67 SD $11.8 \mathrm{~kg}$, mean self-reported height 172.5 SD $9.9 \mathrm{~cm}$ and mean BMI $22.4 \mathrm{SD} 3 \mathrm{~kg} / \mathrm{m}^{2}$. All participants reported noticing the calorie labels by the meals and $71 \%$ of them reported using the labels when choosing their meals. Participants reported the calorie values were of value to allow them to eat healthier and control their body weight. A majority (52\%) of participants would welcome additional nutritional information such as macronutrient content, such as protein and fat values. Within this study design it was not possible to measure any change in calorie content of meals chosen and consumed by the students. Regularly eating out or consuming prepared meals is part of everyday life. Students appeared to value calorific information and further studies to estimate an effect on meal choice are justified.
\end{abstract}

1. Department of Health (2011) http://www.wp.dh.gov.uk/responsibilitydeal/files/2012/01/Technical-Guidance-on-Voluntary-Calorie-Labelling-for-Catering-Businesses.pdf (accessed 10/01/2013). 